\title{
Systemic manifestations of ehlers-danlos syndrome hypermobility type
}

\begin{abstract}
Ehlers-Danlos syndrome Hypermobility type is a hereditary connective tissue disease characterized by generalized joint Hypermobility, joint instability, skin changes and musculoskeletal pain. Signs and symptoms of Ehlers-Danlos syndrome Hypermobility type are classified as musculoskeletal or extra skeletal. Pain and fatigue are the most common complaints in the clinical practice. Due to impaired postural structure and biomechanics, associated conditions include nocturnal insomnia and early morning drowsiness, dysautonomia, dyslexia and neuropsychological disorders and illnesses related to impaired restorative phases of sleep. The patient has musculoskeletal pain that affects the activities of daily life and work, as well as shifting the biological clock. It is therefore important to understand the order of appearance and prevalence of signs and symptoms in the general population suggesting a need to investigate the order of these symptoms in population studies.
\end{abstract}

Keywords: hypermobility, ehlers-danlos hypermobility type, neuropsychological disorders, comorbidities, anxiety, dyslexia, fatigue, pain, collagen
Volume 4 Issue 2 - 2017

\author{
Neuseli Marino Lamari,' Michael Peres de \\ Medeiros, ${ }^{2}$ Mateus Marino Lamari ${ }^{3}$ \\ 'Physiotherapist, Professor of the Medicine School in Sao Jose \\ do Rio Preto (FAMERP), Brazil \\ ${ }^{2}$ Biologist, Medicine School in Sao Jose do Rio Preto (FAMERP), \\ Brazil \\ ${ }^{3}$ Physiotherapist, Foundation Medicine School in Sao Jose do Rio \\ Preto (FUNFARME), Brazil
}

\author{
Correspondence: Neuseli Marino Lamari, Physiotherapist, \\ Professor of the Medicine School in Sao Jose do Rio Preto \\ (FAMERP), Brazil, Tel 55 (I7) 32015700 \\ Email neuseli@famerp.br
}

Received: February 19, 2017| Published: March 28, 2017
Abbreviations: EDS, ehlers-danlos syndrome; EDS-HT, ehlers-danlos syndrome hypermobility type; JH, joint hypermobility; GJH, generalized joint hypermobility; GI, gastrointestinal

\section{Introduction}

Joint Hypermobility (JA) can be the extreme of the range of motion or a condition in a group of hereditary connective tissue disorders. It is influenced by age, gender and ethnicity, has a Gaussian distribution in the physiological range of motion and is considered to be a genetically determined deviation from normality. ${ }^{1,2}$ The JA can be identified in up to $64.6 \%$ of the population, including children. ${ }^{3-7}$ Recently a population study was published that identified JH In $41 \%$ of Brazilian children. Characterization of this disorder is achieved using the Beighton score. Ehlers-Danlos syndrome (EDS) is a hereditary connective tissue disease caused by genetic alterations related to collagen that produce other health conditions. This syndrome is characterized by generalized $\mathrm{JH}$, joint instability and pain. It has multisystem manifestations and clinical variability affecting the skin, ligaments, joints, blood vessels and internal organs. ${ }^{9}$ According to Hamonet et al., ${ }^{10}$ a high frequency of EDS is seen in the clinical practice, but the differences of evaluation systems does not allow reliable calculations of its prevalence to be made. ${ }^{2}$ EDS is classified by the Villefranche criteria into six subtypes with Ehlers-Danlos Syndrome Hypermobility type (EDS-HT) having the highest prevalence. The phenotypic expression of EDS-HT is variable, even within the same family, making diagnosis a challenge ${ }^{9}$ and resulting in under diagnosis of the syndrome. ${ }^{5}$ As the terms Joint Hypermobility Syndrome (JHS) and EDS-HT are often used differently in the same classification, the etiology must be confirmed at the molecular level. ${ }^{11}$ The signs and symptoms of EDS-HT are classified as musculoskeletal or extra skeletal. ${ }^{5} \mathrm{Henkel}^{12}$ cites a study by Grahame ${ }^{1}$ on the main categories of clinical presentation. These include sagging of musculoskeletal tissue, pain in the joints and in the non-inflamed spine, dislocations, soft tissue injuries and problems with support structures, such as the pelvic floor. Moreover the subject suffers amplification of pain, which can lead to muscle intolerance and deconditioning, and finally, psychosocial sequels, anxiety, depression, obesity, isolation and anger. All these conditions are often targeted by medical professionals who are unable to help the patient.

The EDS-HT may have systemic manifestations from the mouth to the anus, some of which are benign, and others may be lethal. A thorough knowledge of gastrointestinal (GI) manifestations and their management is mandatory to avoid unnecessary morbidity and mortality. ${ }^{13-15}$ An increased rate of celiac disease was identified in EDS-HT, suggestive of intestinal malabsorption, a possible factor for fatigue. ${ }^{16,17}$ Moreover, individuals have psychiatric disorders and psychosocial impairment, ${ }^{18}$ and a high prevalence of anxiety disorders from simple phobias to panic disorders. ${ }^{19}$ The EDS-HT is characterized by pain, fatigue, proprioceptive dysfunctions, hemorrhagic syndromes, dysautonomia, dystonia and digestive tract, vesicophrectinal, respiratory, dental, otorhinolaryngological, ophthalmological, gynecological, obstetrical and cognitive disorders, among others. The pains are diffuse and are among the most disabling symptoms in patients with fatigue and proprioceptive disorders; at times, even from early childhood, the whole body is described as painful. ${ }^{20}$ Fatigue and musculoskeletal pain generally receive little medical attention. ${ }^{21}$ Chronic fatigue is present in most patients, manifesting with a persistent sensation of fatigue, lack of energy and feeling of exhaustion, with impairment to concentration. ${ }^{16}$ Pain is the main complaint, with chronicity and consequences on quality of life, including sleep loss, and impaired social and work relationships, sexual function, and physical and recreational activities resulting in depression with psychosocial consequences (Figure 1-14). ${ }^{22}$ 


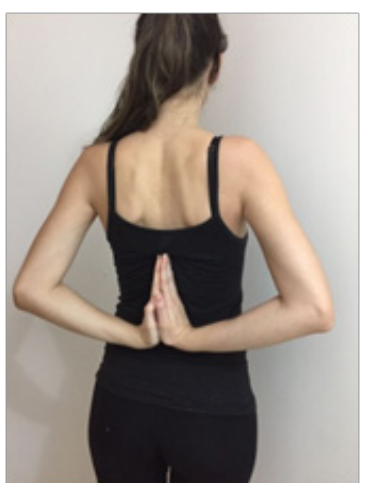

Figure I Shoulder Joint Hypermobility.



Figure 4 Walker-Murdoch wrist test.

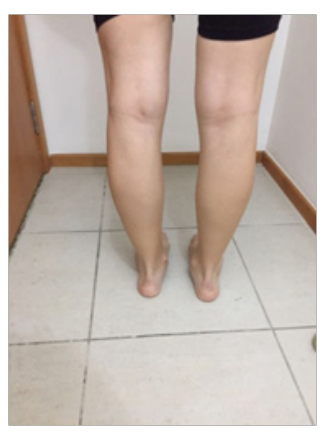

Figure 7 Orthopedic deformities in the feet, posterior view.

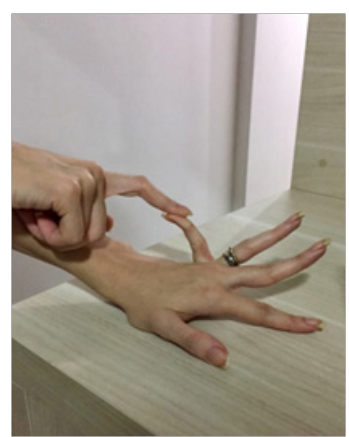

Figure 10 Passive dorsiflexion showing hyperextension of the fifth finger beyond $90^{\circ}$.

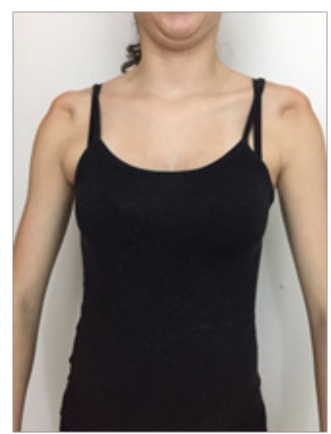

Figure $\mathbf{2}$ Induced dislocation of the shoulder joints, with the limbs down.

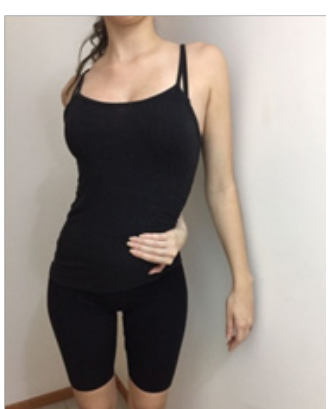

Figure 5 Pass the arm behind the back and touch the navel with the hand, characteristic of hypermobility.

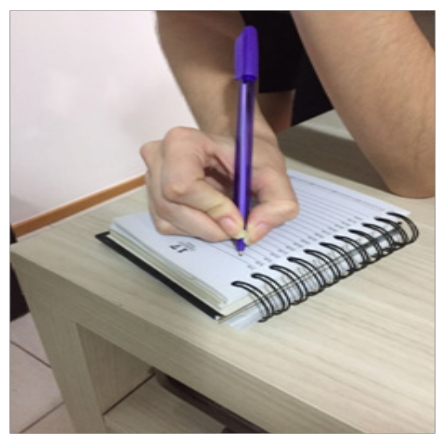

Figure 8 Atypical pen support when writing, characteristic of hypermobility in the fingers

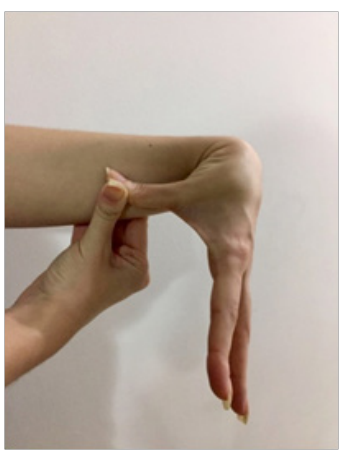

Figure II Passive apposition of the thumb to the flexor region of the forearm

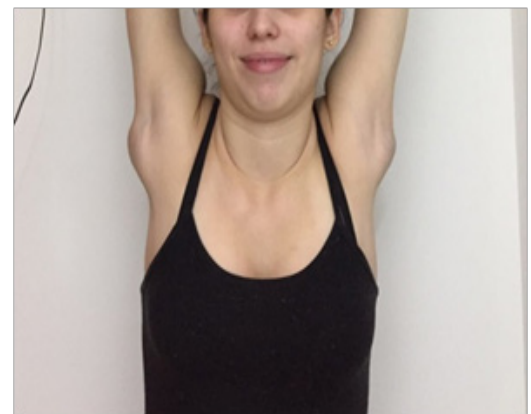

Figure 3 Induced dislocation of the shoulder joints, with the limbs up.

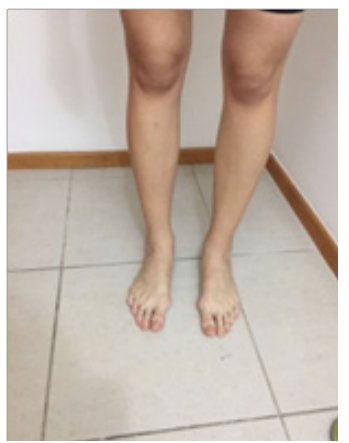

Figure 6 Orthopedic deformities in the feet, anterior view.

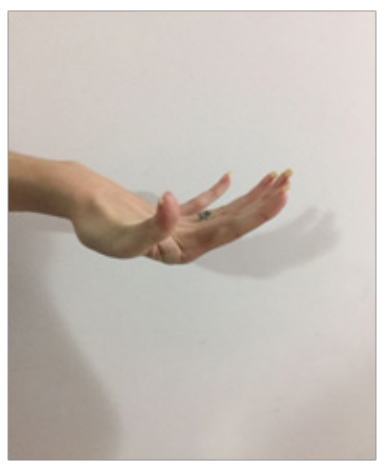

Figure 9 Hand with the "Flying Bird" sign.

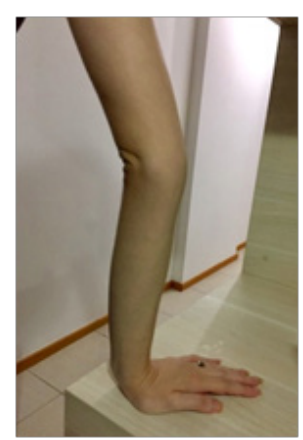

Figure 12 Hyperextension of the elbow joint beyond $10^{\circ}$. 


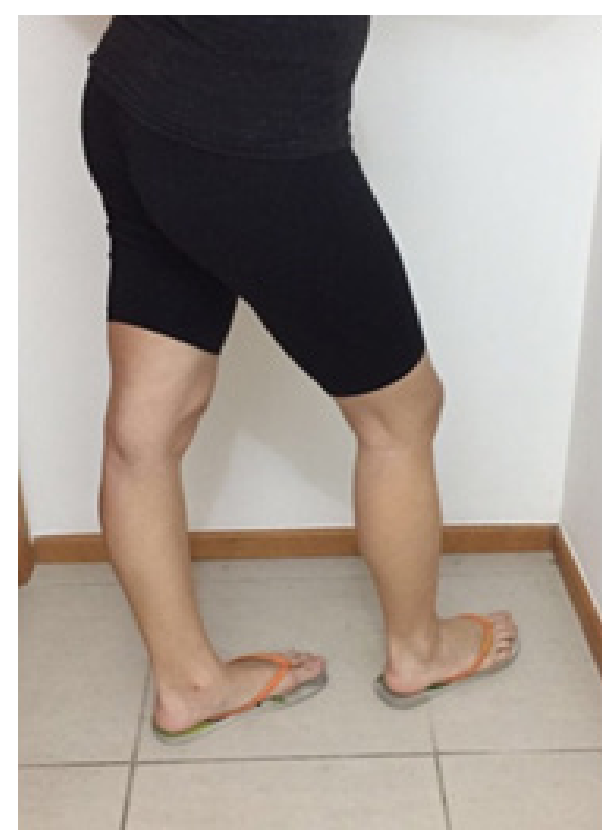

Figure 13 Hyperextension of the knee joint beyond $10^{\circ}$.

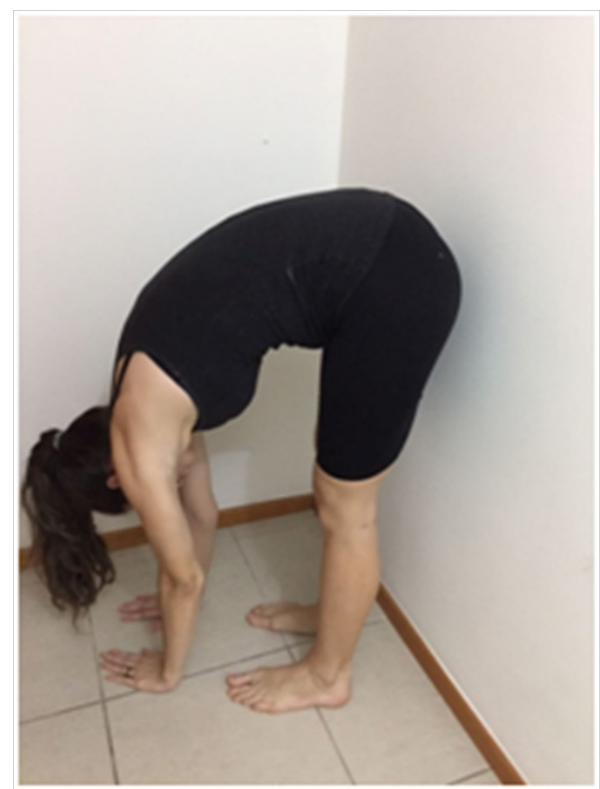

Figure I4 Forward flexion of the trunk, with knees straight, so that the palms of the hands rested easily on the floor.

\section{Methods}

The search strategy of this study was an up-to-date review of the specialized literature on JH, EDS-HT, including the signs, symptoms, diagnoses and comorbidities related to EDS and the different techniques of updating references used by a simple search and their effectiveness. Articles in English, French and Spanish published in the BIREME, SciELO Brazil, LILACS and PUBMED electronic databases from 1973 to 2017 were investigated using the keywords Hypermobility, Ehlers-Dan los, Ehlers-Danlos syndrome Hypermobility type, gastrointestinal motility, sleep disorders, pain, fatigue, dysautonomia, dyslexia and anxiety. Duplicate publications were excluded.

\section{Discussion and conclusion}

The EDS-HT is very common and has systemic manifestations. Pain and fatigue are the most common complaints in the daily clinical practice, followed by nocturnal insomnia and morning drowsiness, dysautonomia, dyslexia and neuropsychological disorders. Furthermore subjects suffer from conditions related to the restorative phases of sleep such as musculoskeletal pain, impaired concentration and cognitive deficits, which are explained, at least in part, by higher organic energy consumption. ${ }^{10,17,18,20,22}$ In this context, there is impairment to activities of daily living, and to the professional and sports life of individuals, a situation that requires an understanding of the order of appearance and prevalence of signs and symptoms in the general population with an emphasis on this diversity of manifestations, a condition that currently suggests analyzes of signs and symptoms based on disturbances of the hyper mobile spectrum.

\section{Acknowledgements}

None.

\section{Conflict of interest}

The author declares no conflict of interest.

\section{References}

1. Grahame R, Bird HA, Child A. The revised (Brighton 1998) criteria for the diagnosis of benign joint hypermobilitysyndrome (BJHS). $J$ Rheumatol. 2000;27(7):1777-1779.

2. Malfait F, Hakim AJ, De Paepe A, et al. The genetic basis of the joint hypermobility syndromes. Rheumatology (Oxford). 2006;45(5):502-507.

3. Forléo LH, Hilário MO, Peixoto AL, et al. Articular hypermobility in school children in Sao Paulo, Brazil. J Rheumatol. 1993;20(5):916-917.

4. Lamari NM, Chueire AG, Cordeiro JA. Analysis of joint mobility patterns among preschool children. Sao Paulo Med J. 2005;123(3):119-123.

5. Bravo JF. Síndrome de Ehlers-Danlos tipo III, llamado también Síndrome de Hiperlaxitud Articular (SHA): Epidemiología y manifestaciones clínicas. Revista Chilena de Reumatologia. 2010;26(2):194-202.

6. Ojeda NE de L, Gonzales DCG. Trastornos hereditarios de la fibra colágena. Revista Cubana de Hematologia, Inmunologia y Hemoterapia. 2014;30(4):405-407.

7. Lamari NM, Lamari MM. Characterization of Brazilian children with joint hyper mobility. Int J Physiatry. 2016:2(2).

8. Beighton P, Solomon L, Soskolne C. Articular mobility in an African population. Ann Rheum Dis. 1973;32(5):413-418.

9. De Paepe A, Malfait F. The Ehlers-Danlos syndrome, a disorder with many faces. Clin Genet. 2012;82(1):1-11.

10. Hamonet C, Gompel A, Mazaltarine G, et al. Ehlers-Danlos Syndrome or Disease? J Syndromes. 2015;2(1):5.

11. Castori M, Morlino S, Celletti C, et al. Re-writing the natural history of pain and related symptoms in the joint hypermobilitysyndrome/ Ehlers-Danlos syndrome, hypermobility type. Am J Med Genet A. 2013;161A(12):2989-3004.

12. Henkel G. Strides in Recognition and Management of Joint Hypermobility Syndrome. Rheumatology. 2010.

13. Solomon JA, Abrams L, Lichtenstein GR. GI Manifestations of Ehlers-Danlos Syndrome. American Journal of Gastroenterology. 1996;91(11):2282-2288. 
14. Castori M, Morlino S, Pascolini G, et al. Gastrointestinal and nutritional issues in joint hypermobilitysyndrome/Ehlers-Danlos syndrome, hypermobility type. Am J Med Genet C Semin Med Genet. 2015;169C(1):54-75.

15. Castori M, Tinkle B, Levy H, et al. A framework for the classification of joint hypermobilityand related conditions. Am JMed Genet C Semin Med Genet. 2017;175(1):148-157.

16. Castori M, Morlino S, Celletti C, et al. Management of pain and fatigue in the joint hypermobilitysyndrome (a.k.a. Ehlers-Danlos syndrome, hypermobility type):principles and proposal for a multidisciplinary approach. Am J Med Genet A. 2012;158A(8):2055-2070.

17. Beckers AB, Keszthelyi D, Fikree A, et al. Gastrointestinal disorders in joint hypermobilitysyndrome/Ehlers-Danlos syndrome hypermobility type:a review for the gastroenterologist. Neurogastroenterol Motil. 2017:29(8).
18. Hershenfeld SA, Wasim S, McNiven V, et al. Psychiatric disorders in Ehlers-Danlos syndrome are frequent, diverse and strongly associated with pain. Rheumatol Int. 2016;36(3):341-348.

19. Bulbena A, Pailhez G, Bulbena-Cabré A, et al. Joint hyper mobility, anxiety and psychosomatics: two and a half decades of progress toward a new phenotype. Adv Psychosom Med. 2015;34:143-157.

20. Hamonet C. Les douleurs dans le syndrome d'Ehlers-Danlos (à propos de 644 cas avec un test de Beighton égal ou supérieur à 4/9). Journal de réadaptation médicale. 2013;33(2):51-53.

21. Voermans NC, Knoop H, Bleijenberg G, et al. Fatigue is associated with muscle weakness in Ehlers-Danlos syndrome: an explorative study. Physiotherapy. 2011;97(2):170-174.

22. Baeza-Velasco C, Gély-Nargeot MC, Bulbena-Vilarrasa A, et al Joint hypermobility syndrome: problems that require psychological intervention. Rheumatol Int. 2011;31(9):1131-1136. 